\title{
Prolonged Cold Storage Affects Pollen Viability and Germination along with Hydrogen Peroxide and Nitric Oxide Content in Rosa bybrida
}

\author{
Anca MACOVEI ${ }^{1}$, Matteo CASER $^{2}$, Mattia DONÀ $^{1,4}$, Alberto VALASSI $^{1}$, \\ Annalisa GIOVANNINI ${ }^{3}$, Daniela CARBONERA ${ }^{1}$, \\ Valentina SCARIOT ${ }^{2}$, Alma BALESTRAZZI ${ }^{1 *}$ \\ IUniversitadegliStudidi Pavia, Departmentof Biology and Biotechnology Lazzaro Spallanzani, via Ferrata 9,27100, Pavia, Italy; alma.balestrazzi@unipv.it \\ ${ }^{2}$ Universita degli Studidi Torino, Department of Agricultural Forestand Food Sciences, Largo Paolo Bracini 2, 10095, Grugliasco, Torino, Italy \\ ${ }^{3}$ Consiglioperla Ricerca in Agricoltura el'Analisidell'Economia Agraria (CREA), Unitàdi Ricercaperla Floricoltura ele Specie Ornamentali (FSO), \\ corso Inglesi 508, 18038 Sanremo (Imperia), Italy \\ ${ }^{4}$ Present Address: Gregor MendelInstitute (GMI), Austrian Academy of Sciences,Vienna Biocenter (VBC),Dr.Bohr Gasse 3, 1030 Vienna, Austria
}

\begin{abstract}
Roses (Rosa hybrida) are the most important ornamental cut-flowers and breeders' main focus is to develop new desirable modern cultivars. Rose breeding programs center on the introduction of new flower colors, thornless stems, higher production and good post-harvest performance. The study of the main pollen traits, such as pollen quantity and quality, viability, longevity, morphological homogeneity, germination and tube growth, is important for building suitable breeding programs. Recently, a number of studies have shown that reactive oxygen species, like hydrogen peroxide, and nitric oxide, are involved in a wide range of signaling processes including pollen tube growth and pollen-pistil recognition. Pollen viability after anther dehiscence is crucial for successful crossbreeding. In the present work, pollen grains from 5 hybrid tea rose cultivars were stored at $-20^{\circ} \mathrm{C}$ up to 12 months. Pollen viability and germination rate was monitored in order to provide useful information about pollen storage length. Additionally, pollen grains were tested for their content in hydrogen peroxide and nitric oxide by using a novel approach where the fluorescence is read in a quantitative RealTime PCR (qRT-PCR) machine. Pollen viability and in vitro pollen germination capacity varied among the rose genotypes, while a progressive decrease was evidenced during 12 months of storage at low temperature. Both hydrogen peroxide and nitric oxide production were found to be genotypedependent, whilst accumulation of the two molecules was observed during the storage period. A putative detrimental effect of these molecules during pollen conservation is hypothesized.
\end{abstract}

Keywords: hybrid tea rose, pollen conservation, pollen grains, reactive nitrogen species (RNS), reactive oxygen species (ROS)

\section{Introduction}

Rose breeding programs have a long history throughout centuries (Scariot et al., 2006; De Cock et al., 2007). Nowadays, the breeding programs are mainly focused on new desirable cultivars with novel flower colors, thornless stems, higher production, and prolonged post-harvest performance, but some major problems related to poor seed production and germination are frequently encountered (Pipino et al., 2011a; Pipino et al., 2012; Caser et al., 2014; Bosco et al., 2015). Cultivated roses often show reduced pollen viability resulting from male meiotic or post-meiotic aberrations (Jacob and Ferrero, 2003). To avoid the risk of very low seed production, breeders commonly use high pollen quantities from a limited number of male parents chosen for their known fertility and often need to overcome asynchrony in flowering among crossing parents by storing pollen (Zlesak 2006; Pipino et al., 2011b).

Pollen viability is quickly lost if grains are left unprotected at room temperature; though, when stored at cold temperatures, pollen viability is kept for a longer period of time which varies among cultivars (Giovannini et al., 2015). Hence, a key aspect in breeding programs is linked to pollen conservation along with the identification of parameters related to pollen fertility and viability. This is of outmost importance and can aid to increase the overall efficiency of breeding programs.

Pollen preservation is dependent on aging and, consequently, some common features can be envisaged with the seed system, in which most of the damage associated with aging results from reactive oxygen (ROS) and reactive nitrogen species (RNS) production during seed desiccation and prolonged storage 
(Donà et al., 2013a). Besides, ROS and RNS are key components in seed signal transduction pathways, and it has been hypothesized that seed germination can be completed only when the ROS content is maintained under a critical threshold that allows the induction of ROS-mediated signaling mechanisms (Balestrazzi et al., 2011; Ventura et al., 2012). Therefore, several tools tested on seeds could be expanded also for pollen investigations. Recently, it has been shown that nitric oxide (NO), a main constituent of RNS, is involved in plant reproductive processes (Zafra et al., 2010). Moreover, hydrogen peroxide $\left(\mathrm{H}_{2} \mathrm{O}_{2}\right)$, a key player among $\mathrm{ROS}$, has a role to play in pollen tube growth and pollen-pistil interactions (Speranza et al., 2012). However, the elucidation of the roles played by these molecules within the plant gametes is still incipient.

In the present study, pollen grains collected from five hybrid tea rose cultivars were stored at $-20^{\circ} \mathrm{C}$ up to 12 months. Pollen viability and germination rate were monitored in order to provide breeders with useful information about pollen storage length. In addition, $\mathrm{H}_{2} \mathrm{O}_{2}$ and $\mathrm{NO}$ content were measured in fresh and stored pollen grains at indicated time points to evaluate their eventual role as possible viability markers. The acquired information can assist breeders in setting up more effective breeding strategies for hybrid tea rose varieties.

\section{Materials and Methods}

\section{Plant material}

Pollen grains from five commercial Rosa bybrida cultivars ('Dolphin', 'Golden Fashion', 'New Fashion', 'Swan' and 'Touch of Class') were provided by NIRP International (Bevera, Imperia, Italy). Anthers were placed at room temperature in open petri dishes to favor pollen release and drying. After two days, fresh pollen was used either for further analysis or stored at $-20{ }^{\circ} \mathrm{C}$ for a total of 12 months. Intermediate analyses were performed at 3,6 and 12 months of conservation.

\section{Pollen viability and germination rate}

Pollen viability was assessed by TTC (Tryphenil Tetrazolium Chloride) staining as previously reported (Eti, 1991). In vitro pollen germination was assessed on PGM medium ( $40 \mathrm{mg} \mathrm{L}-1 \mathrm{H}_{3} \mathrm{BO}_{3}, 152 \mathrm{mgL}-1 \mathrm{CaCl}_{2}\left(\mathrm{H}_{2} \mathrm{O}\right), 150 \mathrm{gL}$ 1 sucrose, $7 \mathrm{~g} \mathrm{~L}-1$ agar, pH 5.6) (Leus, 2005). Samples were evaluated after $24 \mathrm{~h}$ incubation at $22 \pm 2{ }^{\circ} \mathrm{C}$ under dark conditions. Pollen grains were considered as germinated when the pollen tube reached a length of at least 1.5 times its diameter (Leus, 2005). The observations were performed using a Reichert Biovar microscope (Reichert, Germany) (100x), with incorporated Olympus C-5000 photocamera. All analyses were performed in triplicate (100 pollen grains scored for each slide).

\section{Detection of hydrogen peroxide and nitric oxide}

$\mathrm{H}_{2} \mathrm{O}_{2}$ and NO levels were measured by staining the pollen grains with dichlorodihydrofuorescein diacetate (DCFH-DA, Sigma-Aldrich, Milan, Italy) and diaminofluorescein diacetate (DAF $2-\mathrm{DA}$, Sigma-Aldrich), respectively (Pasqualini et al., 2011). The pollen ( $1 \mathrm{mg}$ ) was incubated for $15 \mathrm{~min}$ with $10 \mu \mathrm{M}$ DCFH-DA, and for $30 \mathrm{~min}$ with $10 \mu \mathrm{M}$ DAF2-DA. Relative fluorescence was determined at $\lambda=517 \mathrm{~nm}$ in a Rotor-Gene 6000 PCR apparatus (Corbett Robotics, Brisbane, Australia), setting the program for one cycle of $30 \mathrm{~s}$ at $25^{\circ} \mathrm{C}$. As a positive control, pollen grains were subjected to heat shock $(10 \mathrm{~min}$, $65^{\circ} \mathrm{C}$ ). The relative fluorescence (represented as RFU) was calculated by normalizing the samples to controls. Photos were taken using a ZEISS Axioplan microscope equipped with a CCD (Computer Coupled Device) videocamera (Photometrics, Arizona, USA). All analyses were performed in triplicate.

\section{Statistical analysis}

Arcsine transformation was performed on all percent incidence data before statistical analysis in order to improve homogeneity of variance. Effects of genotype and storage duration on the analysed traits were evaluated by one-way ANOVA using Ryan-Einot-Gabriel-Welsch's multiple stepdown F (REGW-F) test $(p \leq 0.05)$. All analyses were performed with SPSS 21.0 Inc. software(Chicago, Illinois, USA).

\section{Results and Discussion}

Changes in pollen viability and germination rate during storage at $-20^{\circ} \mathrm{C}$

For this study, five cultivars ('Golden Fashion', 'Dolphin', 'Swan', 'Touch of Class', 'New Fashion') with high fertility pollen, based on their diameter larger than $30 \mu \mathrm{m}$ (Pipino et al. 2011b), were selected; these cultivars were also suggested by NIRP International, provider of the used material, as cultivars with high potential for breeding programs. The pollen aspect during TTC coloration and pollen grain germination is shown in Fig. $1 \mathrm{~A}$ and $\mathrm{B}$, respectively. The changes in pollen viability and germination rate during one year of storage at $-20{ }^{\circ} \mathrm{C}$ are presented in Fig. $1 \mathrm{C}$ and D. In fresh pollen (month 0 ), the pollen viability ranged from a minimum of $72.3 \%$ in 'Golden Fashion' to a maximum of $83.3 \%$ in 'Dolphin', without significant differences. After 3 months of conservation only a slight decrease (from $81.2 \%$ to $71.0 \%$ ) in pollen viability belonging to 'Swan' cultivar was observed. In the other cultivars, the pollen viability strongly decreased between 3 and 6 months of conservation, reaching the lowest values at 12 months, with the lowest reduction ( 65\%) in 'Dolphin' and 'Touch of Class' and the highest ( 86\%) in 'Swan' (Fig. 1C). When the fresh pollen germination rate was investigated, none of the tested cultivars presented a germination percentage above $50 \%$ (Fig. 1D). The pollen germination rate ranged from $26.8-27.1 \%$ in 'New Fashion' and 'Touch of Class' to 46.4-47.0-49.0\% in 'Swan', 'Golden Fashion' and 'Dolphin', respectively. After 3 months only a slight decrease in 'New Fashion' (from 26.8\% to 21.0\%) was observed. Similarly to pollen viability, the conservation at low temperature affected the germination rate between the months 3 and 6. The lowest percentages were counted after 12 months with the lowest reduction $(\sim 75 \%)$ in 'Touch of Class' (from $27.1 \%$ to $6.7 \%$, respectively) and the highest $(\sim 93 \%)$ in 'Golden Fashion' and 'Swan' (from $47.0 \%$ to $3.3 \%$ and from $46.4 \%$ to $3.3 \%$, respectively). Similar findings were recorded in $R$. dumalis and $R$. villosa (Ercisili, 2007), as well as in other six $R$. bybrida commercial cultivars (Giovannini et al., 2015). The decrease in pollen viability during storage condition may be due to dehydration, resulting in loss of pollen colloidal properties (Pacini, 2000; Franchi et al., 2011).

\section{Hydrogen peroxide and nitric oxide production during storage at $-20^{\circ} \mathrm{C}$}

The levels of $\mathrm{H}_{2} \mathrm{O}_{2}$ and $\mathrm{NO}$ in hybrid tea rose pollen grains were measured using the standard technique of DCFH-DA and 

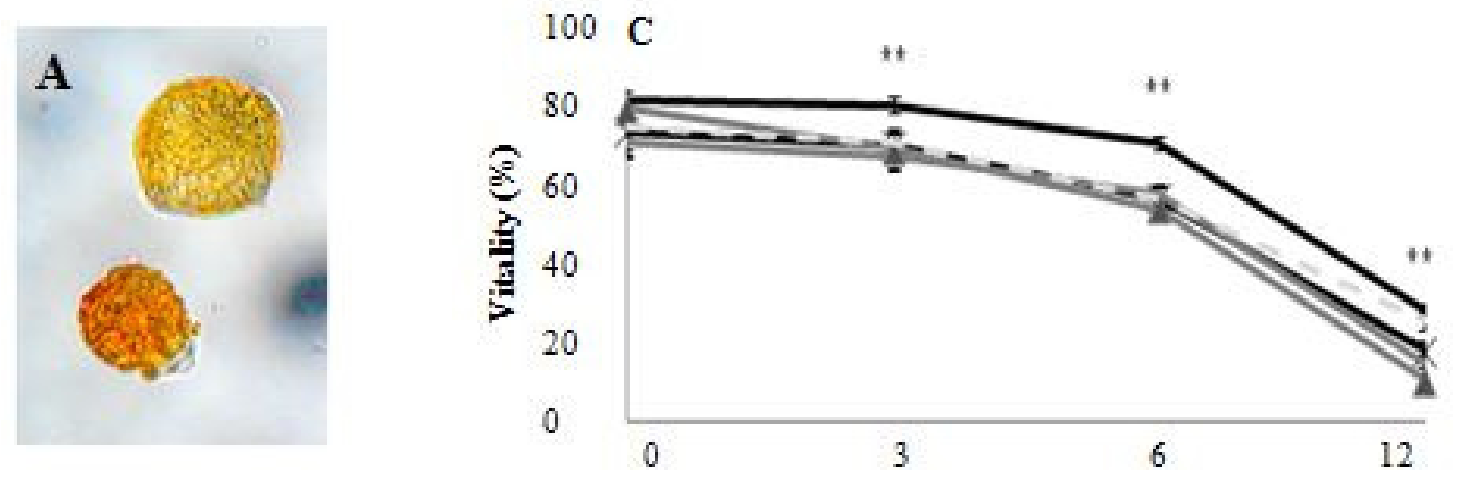

100

D
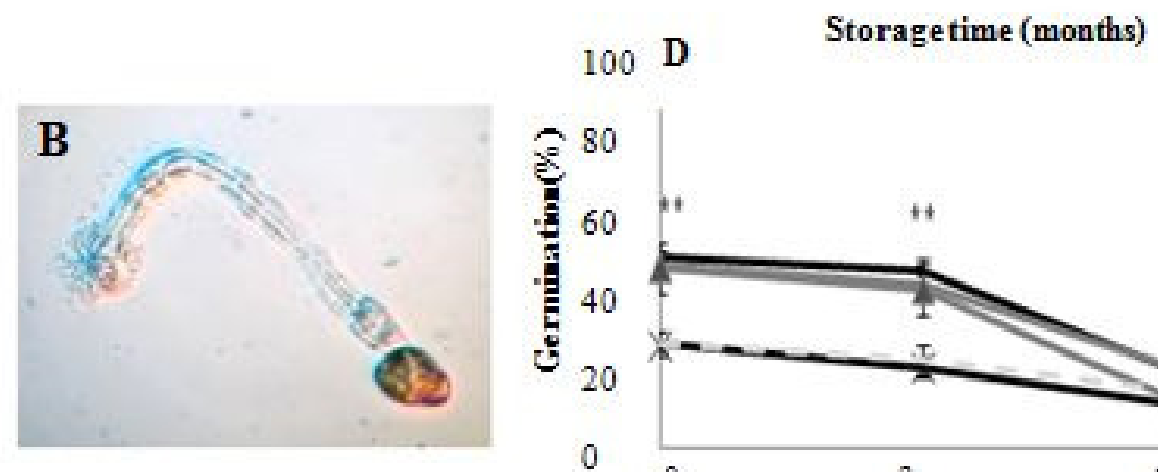

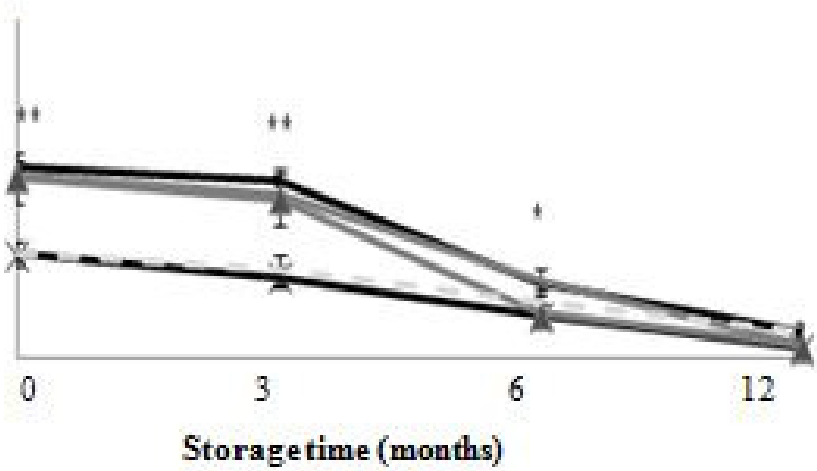

Fig. 1. Evaluation of hybrid tea rose pollen viability and germination during cold storage. (A) Pollen grains stained with TTC. (B) Germinated pollen grain. (C) Dynamics of pollen viability (C) and germination rate (D) in 5 selected hybrid tea rose cultivars ('Dolphin', solid black line; 'New Fashion', solid black line with X; 'Golden Fashion', solid dark grey line; 'Swan', solid dark grey line with $\boldsymbol{\Delta}$; 'Touch of Class', dotted light grey line). Asterisks indicate the significance of differences between genotypes as determined by one-way ANOVA and REGW-F comparison tests $\left({ }^{*}=\mathrm{P}<0.05,{ }^{* *}=\mathrm{P}<0.001\right)$. Vertical bars indicate \pm standard error, $\mathrm{n}=5$.

DAF2-DA staining, but with improvements regarding the detection of fluorescence by using a qRT-PCR machine (Donà et al., 2013b). Additionally, images of stained pollen grain with DCFH-DA and DAF2-DA are shown in Fig. 2A and B, respectively. The results showed that the $\mathrm{H}_{2} \mathrm{O}_{2}$ and $\mathrm{NO}$ content varied among the tested cultivars (Fig. $2 \mathrm{C}$ and $\mathrm{D}$ ). In fresh pollen (month 0 ), $\mathrm{H}_{2} \mathrm{O}_{2}$ varied significantly among cultivars (Fig. 2C). After 3 months of conservation a significant increase in $\mathrm{H}_{2} \mathrm{O}_{2}$ and NO levels were observed in 'New Fashion' and 'Dolphin'. Later, at 6 and 12 months, the highest values appeared in 'Touch of Class' and 'Dolphin' (7.4 and 10.6-fold, 4.6- and 5.5-fold, respectively, as compared with the fresh pollen content). In the other cultivars, $\mathrm{H}_{2} \mathrm{O}_{2}$ content kept constant during the experiment without significant variations. Concerning the $\mathrm{NO}$ content, in fresh pollen (month 0 ) significant differences were observed among cultivars, while no variations were found after the first 3 months of storage in all the studied cultivars (Fig. 2D). On the other hand, at 6 and 12 months a significant increase, between 2- to 4-fold, was observed in 'Touch of Class', 'Dolphin', and 'Swan'. The other cultivars kept constant content during all the experiment without significant differences.

In this study the $\mathrm{H}_{2} \mathrm{O}_{2}$ and $\mathrm{NO}$ production resulted to be cultivar dependent, with high levels of accumulation after 6 months of storage, mostly in 'Touch of Class' and 'Dolphin'. In addition, their levels appear to have an interrelation with the loss of pollen viability and germination during cold storage conditions. Similarly, when the pollen of Paeonia suffruticosa, Paulownia tomentosa and Ambrosia artemisiifolia were exposed to ultraviolet radiations (UV-B) or ozone (O3) fumigation, $\mathrm{H}_{2} \mathrm{O}_{2}$ and $\mathrm{NO}$ generation was detected and correlated with a reduction of in vitro pollen germination and tube growth ( $\mathrm{He}$ et al., 2006; Pasqualini et al., 2011).

\section{Conclusion}

Our study indicates that hybrid tea rose pollen can be efficiently stored at $-20{ }^{\circ} \mathrm{C}$ up to 3 months. Longer storage periods affected pollen viability and germination, with the highest impact after 12 months of storing. Thus, our study provides key information for rose breeders regarding rose pollen storing time. Moreover, the $\mathrm{H}_{2} \mathrm{O}_{2}$ and $\mathrm{NO}$ content could represent a marker to assess the loss of pollen viability and germination during cold storage conditions; however, further studies which include more cultivars are needed to validate this result. Future investigations pointed to elucidate the crosstalk between ROS and RNS and define improved storage methods suitable for prolonged pollen longevity are still required. 

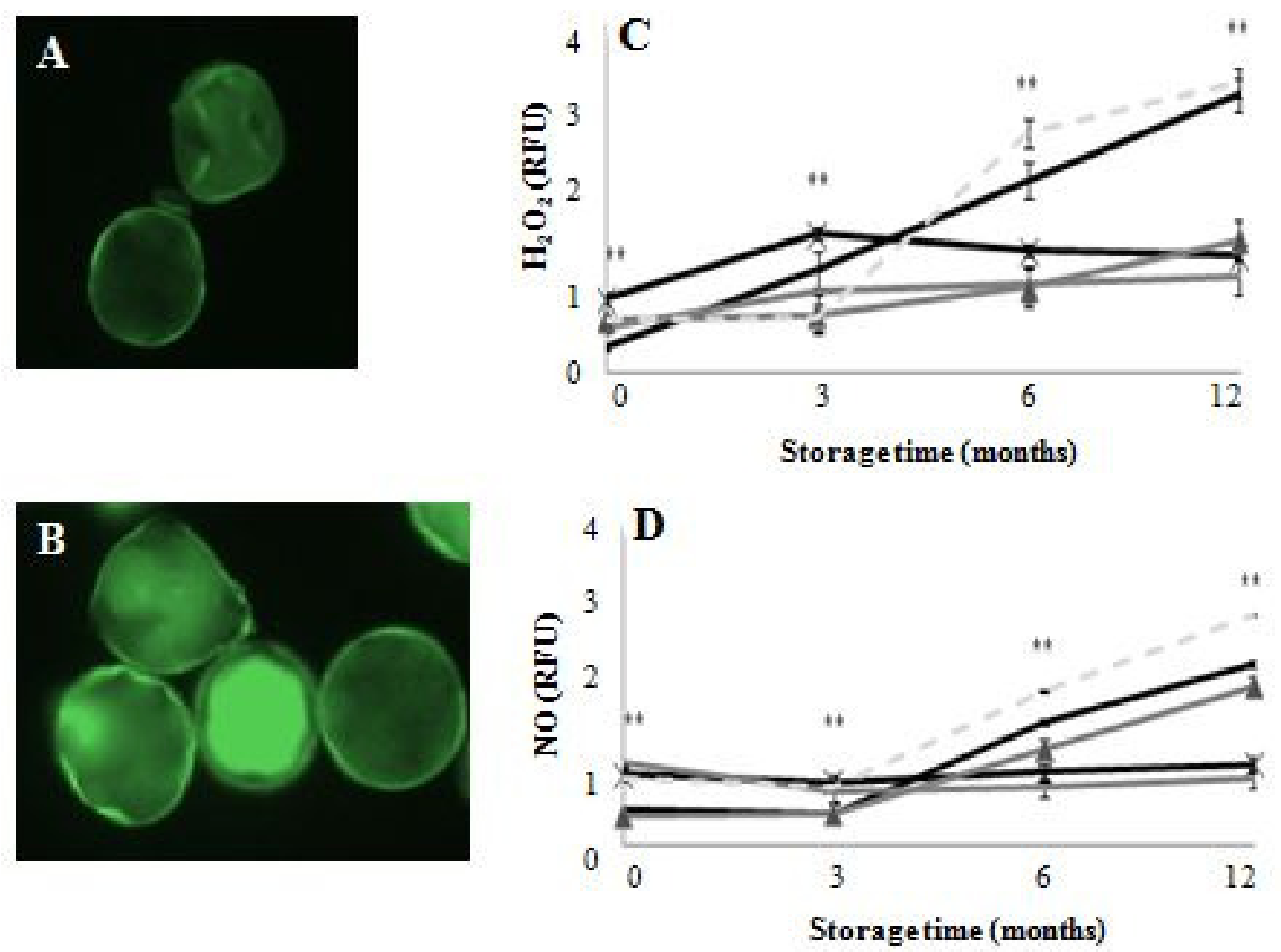

Fig. 2. Evaluation of hybrid tea rose pollen viability and germination during cold storage. (A) Pollen grains stained with TTC. (B) Germinated pollen grain. (C) Dynamics of pollen viability (C) and germination rate (D) in 5 selected hybrid tea rose cultivars ('Dolphin', solid black line; 'New Fashion', solid black line with X; 'Golden Fashion', solid dark grey line; 'Swan', solid dark grey line with $\boldsymbol{\Delta}$; 'Touch of Class', dotted light grey line). Asterisks indicate the significance of differences between genotypes as determined by one-way ANOVA and REGW-F comparison tests $\left({ }^{*}=\mathrm{P}<0.05,{ }^{* *}=\mathrm{P}<0.001\right)$. Vertical bars indicate \pm standard error, $\mathrm{n}=5$.

\section{Acknowledgement}

Authors would like to thank Andrea Mansuino and Gian Guido Ghione (NIRP International) for providing the rose pollen, and Leen Leus for valuable support. The research was supported by the 'MUTROS-OIGA' project (D.M. 18829) from the Italian Ministry of Agriculture MIPAAF.

\section{References}

Balestrazzi A, Confalonieri M, Macovei A, Carbonera D (2011). Seed imbibition in Medicago truncatula Gaertn. expression profiles ofDNA repair genes in relation to PEG-mediated stress. Journal of Plant Physiology 168:706-713.

Bosco R, Caser M, Ghione GG, Mansuino A, Giovannini A, Scariot V (2015). Dynamics of abscisic acid and indole-3-acetic acid during the early-middle stage of seed development in Rosa bybrida. Plant Growth Regulation 75:265-270.

Caser M, Dente F, Ghione GG, Mansuino A, Giovannini A, Scariot V (2014).Shortening of selection time of Rosa hybrida by in vitro culture of isolated embryos and immature seeds. Propagation of Ornamental Plants 14:139-144.
De Cock K, Scariot V, Leus L, De Riek J, Van Huylenbroeck J (2007) Understanding genetic relationships of wild and cultivated roses and the use of species in breeding. CAB Reviews: Perspectives in Agriculture, Veterinary Science, Nutrition and Natural Resources 2No. 052.

Donà M, Balestrazzi A, Mondoni A, Rossi G, Ventura L, Buttafava A, Macovei A, Sabatini ME, Valassi A, Carbonera D (2013a). DNA profiling, telomere analysis and antioxidant properties as tools for monitoring ex situ seed longevity. Annals of Botany 111:987-998.

Donà M, Ventura L, Balestrazzi A, Buttafava A, Carbonera D, Confalonieri M, Giraffa G, Macovei A (2013b). Dose-dependent reactive species accumulation and preferential double strand breaks repair are featured in the $\gamma$-ray response in Medicago truncatula cells. Plant Molecular Biology Reporter 32:129-141.

Ercisili S (2007). Determination of pollen viability and in vitro pollen germination of Rosa dumalis and $R$. villosa. Bangladesh Journal of Botany 36:185-187.

EtiS (1991). Determination of pollen viability and germination capability of some fruit species and cultivars by different in vitro tests. Journal of Agricultural Faculty Cukurova University 6:69-80. 
10

Franchi GG, Piotto B, Nepi M, Baskin CC, Baskin JM, Pacini E (2011). Pollen and seed desiccation tolerance in relation to degree of developmental arrest, dispersal and survival. Journal of Experimental Botany 62:1-15.

Giovannini A, Macovei A, Donà M, Valassi A, Caser M, Mansuino A, Ghione GG, Carbonera D, Scariot V, Balestrazzi A (2015). Pollen grain preservation at low temperatures in valuable commercial rose cultivars. ActaHorticulturae 1064:63-69.

He JM, Liu ZH, Xu H, She XP, Huang C (2006). The involvement of hydrogen peroxide in UV-B-inhibited pollen germination and tube growth of Paeonia suffruticosa and Paulownia tomentosa in vitro. Plant Growth Regulation 49:199-208.

Jacob Y, Ferrero F (2003). Pollen Grains and Tubes. In: Roberts AV, Debener T, Gudin S(Eds). Encyclopedia of Rose Science Vol2, Elsevier pp518-523.

Leus L (2005). Resistance breeding for powdery mildew (Podosphaera pannosa) and black spot (Diplocarpon rosae) in roses. $\mathrm{PhD}$ Thesis, Faculty of Bioscience Engineering, Ghent University, Belgium.

Pacini E (2000). From anther and pollen ripening to pollen presentation. Plant Systematics and Evolution 222:19-43.

Pasqualini S, Tedeschini E, Frenguelli G, Wopfner N, Ferreira F, D'Amato G, Ederli L (2011). Ozone affects pollen viability and $\mathrm{NAD}(\mathrm{P}) \mathrm{H}$ oxidase release from Ambrosia artemisiifolia pollen. Environmental Pollution 159:2823-2830.

Pipino L, Scariot V, Gaggero L, Mansuino A, Van Labeke MC, Giovannini A (2011a). Enhancing seed germination in hybrid tea roses. Propagation ofOrnamental Plants 11:111-118.
Pipino L, Van Labeke MC, Mansuino A, Scariot V, Giovannini A, Leus L (2011b). Pollen morphology as fertility predictor in hybrid tea roses. Euphytica 178:203-214.

Pipino L, Leus L, Scariot V, Van Labeke MC (2012). Embryo and hip development in hybrid roses. Plant Growth Regulation 69:107-116.

Scariot V, Akkak A, Botta R (2006). Characterization and genetic relationships of wild species and old garden roses based on microsatellite analysis. Journal of American Society of Horticultural Science 131:6673.

Speranza A, Crinelli R, Scoccianti V, Geitmann A (2012). Reactive oxygen species are involved in pollen tube initiation in kiwifruit. Plant Biology 14:6476.

Ventura L, Donà M, Macovei A, Carbonera D, Buttafava A, Mondoni A, Rossi G, Balestrazzi A (2012). Understanding the molecular pathways associated with seed vigor. Plant Physiology and Biochemistry 60:196206.

Zafra A, Rodríguez-García MI, de Dios AlchéJ (2010). Cellular localization of ROS and $\mathrm{NO}$ in olive reproductive tissues during flower development. BMC Plant Biology 10:36-50.

Zlesak DC (2006). Rose: Rosa $\times$ hybrida. In: Anderson NO (Eds). Flower Breeding and Genetics: Issues, Challenges and Opportunities for the 21st Century, Springer pp 695-738. 